\title{
Partial duplication of the long arm of chromosome 6: a clinically recognisable syndrome
}

\author{
Enikö K Pivnick, Mazin B Qumsiyeh, Avirachan T Tharapel, John B Summitt, R Sid Wilroy
}

\begin{abstract}
Reciprocal translocations involving the short arm of acrocentric chromosomes can segregate to produce partial duplications without associated deletions. We present a case of an infant with a $46, X Y,-15$, $+\operatorname{der}(15), t(6 ; 15)(q 23 ; p 12)$ pat chromosome complement. The infant had multiple congenital abnormalities including cranial anomalies, facial dysmorphism, anterior webbing of the neck, cardiac anomalies, and joint contractures. From a comparison of the infant's phenotype with 20 other patients with a similar duplication, it is evident that partial duplication of the long arm of chromosome 6 is a clinically diagnosable syndrome.
\end{abstract}

During meiosis the translocated chromosomes of a balanced translocation carrier can segregate to produce gametes with duplications, deletions, or a combination of both. If such gametes are involved in fertilisation, the resulting zygotes may exhibit duplication, deletion, or both duplication and deletion. Patients with tandem duplications, insertions, or derivative chromosomes resulting from translocations involving the short arm of acrocentric chromosomes often show pure duplication for chromosomal segments. The short arms of acrocentric chromosomes contain terminal satellites attached to the centromere by a stalk. The stalk represents the nucleolar organising region (NOR). The NOR carries genes for ribosomal RNA 18s and 28s. The loss of the short arms of a few acrocentric chromosomes appears to be insignificant, as indicated by the normal phenotype seen in balanced Robertsonian translocation carriers. ${ }^{1}$

Duplication or partial trisomy of the distal long arm

Division of Genetics, Department of Pediatrics, University of Tennessee, Memphis, 711 Jefferson Avenue, Memphis, TN 38163, USA.

E K Pivnick, M B Qumsiyeh, A T Tharapel, J B Summitt, R S Wilroy

Correspondence to Dr Pivnick.

Received for publication 15 February 1990.

Accepted for publication 2 March 1990. of chromosome 6 has characteristic clinical manifestations. Since the publication of the initial case by de Grouchy et $a l^{23}$ at least 19 additional cases have been published. While having common characteristics, these patients also have inconsistent phenotypic features. These inconsistent features may be attributed to the length of the duplicated segment of chromosome 6 or to the deleted segment of the second chromosome involved in the translocation.

Three of the previously reported patients had duplication for the distal long arm of chromosome 6 owing to translocation with the short arms of acrocentric chromosomes. ${ }^{3-5}$ Essentially these patients show pure duplication of the distal long arm of chromosome 6. A fourth case with duplication $6 \mathrm{q} 23 \rightarrow \mathrm{qter}$ derived from a paternal $\mathrm{t}(6 ; 15)(\mathrm{q} 23 ; \mathrm{p} 12)$ is presented along with a phenotype-karyotype correlation of such patients.

\section{Case report}

The proband was the product of the second pregnancy of a non-consanguineous, 24 year old mother and a 22 year old father. Their first pregnancy ended in spontaneous abortion during the fifth month of gestation. Necropsy or other studies were not

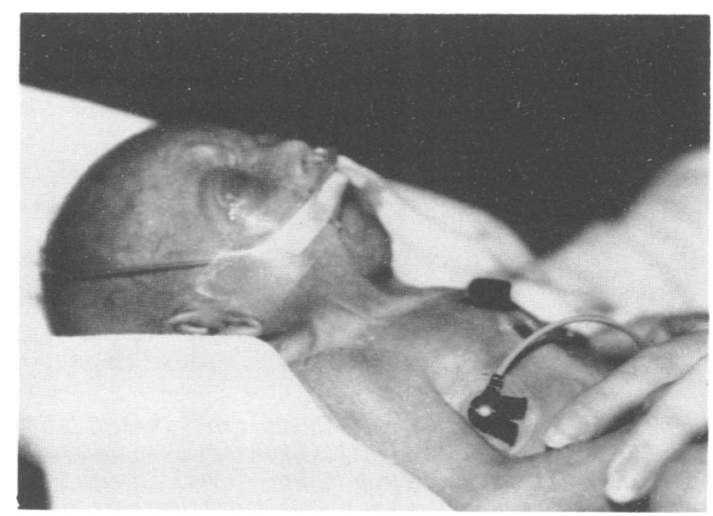

Figure 1 The proband showing the characteristic anterior webbing of the neck. 
performed on the abortus. Both parents were in good health at the time of the proband's conception. The mother denied taking medications, drinking alcohol, or exposure to environmental toxins, rubella, or other known teratogens during pregnancy. However, she smoked one to two packets of cigarettes a day.

Delivery was at term. Cry and respiration were delayed. The patient was intubated for a brief period

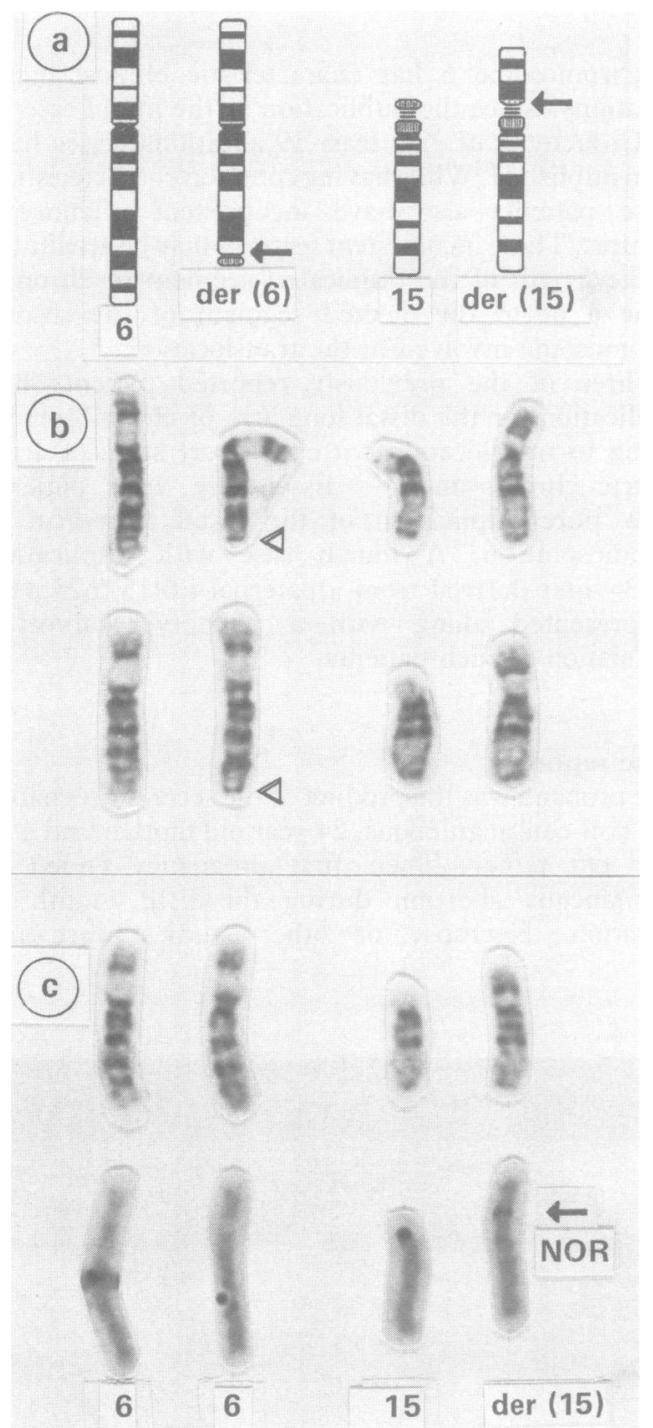

Figure 2 (a) Ideogram showing balanced $t(6 ; 15)(q 23 ; p 12)$. Arrows indicate breakpoints. (b) GTG banded chromosomes 6 and 15 showing the balanced translocation. (c) GTG banded chromosomes of proband showing two normal chromosomes 6 , one normal 15, and the derivative 15 (top). Silver nitrate stained chromosomes 6 and 15 of the proband. Note the NOR region on the derivative chromosome 15 (bottom). after delivery and received oxygen. Birth weight $(1900$ g), head circumference $(29 \mathrm{~cm})$, and crown-heel length $(46 \mathrm{~cm})$ were at or below the 5 th centile. Multiple congenital anomalies noted at birth included acrocephaly, microcephaly, downward slanting palpebral fissures, telecanthus, micrognathia, short neck with anterior webbing, carp shaped mouth, joint contractures, and club feet (fig 1). Examination of the heart indicated a grade III/VI systolic murmur with a loud click heard best at the left sternal border. Echocardiogram showed severe valvular pulmonary stenosis. Ultrasound of the head and kidneys showed no abnormalities. Hyperglycaemia developed neonatally and required insulin therapy. Serum glucose levels fluctuated between 440 and $1137 \mathrm{mg} / \mathrm{dl}$. Corrective cardiac surgery was performed. The patient died of fulminant sepsis at 2 months of age. Permission for necropsy was denied.

\section{CYTOGENETICS}

Chromosome analysis of peripheral blood lymphocytes and skin fibroblasts showed 46 chromosomes. However, each cell showed one chromosome 15 with an unusually large short arm. Chromosome analyses of the father's lymphocytes showed a balanced reciprocal translocation between a chromosome 6 and 8 a 15 involving bands $6 \mathrm{q} 23$ and $15 \mathrm{pl}$, respectively. Extended family studies showed other members whoo were carriers of this balanced translocation. GTG and? QFQ banding clearly showed the satellite (15pl3) translocated to 6q23 (fig 2a and b). NOR staining confirmed the breakpoint on chromosome 15 to be distal to the nucleolar organising region (fig 2c). Thus, the infant's karyotype was interpreted as $46, \mathrm{XY},-15,+\operatorname{der}(15), \mathrm{t}(6 ; 15)(\mathrm{q} 23 ; \mathrm{p} 12)$ pat.

\section{Discussion}

The known clinical and cytogenetic data on 21 patients with duplication of the distal long arm of chromosome 6 are summarised in the table. In four patients the duplication resulted from inherited insertions or inversions. ${ }^{6-8}$ The case reported by Schroer $\mathrm{et}_{\mathrm{al}} \mathrm{l}^{8}$ represents both duplication and deletion, while the other three represent pure trisomies for $6 \mathrm{q} 15 \rightarrow \mathrm{q} 27$ or $6 \mathrm{q} 13 \rightarrow \mathrm{q} 21$. In 13 cases the duplications resulted from a derivative chromosome inherited from a parent with a reciprocal translocation. Therefore, these patients have a 'double syndrome' involving both duplication $6 \mathrm{q}$ and deletion of a segment of a second chromosome.

In the remaining three cases ${ }^{3-5}$ and in the present case, the partial duplication resulted from the inheritance of the derivative acrocentric chromosome with the $6 \mathrm{q}$ region translocated to its short arm. Since the deletion of the satellites or their stalk has no contri- 


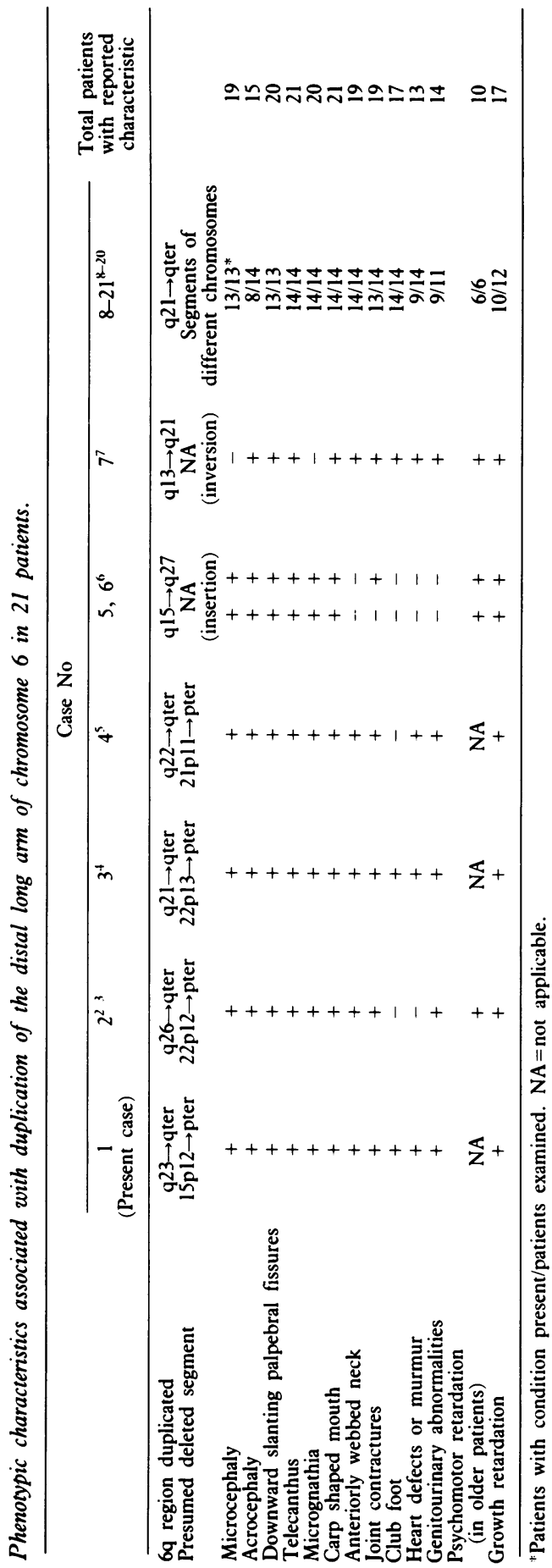

buting effect on the phenotype, these patients do not have an associated deletion syndrome.

The ratio of males to females in the 21 cases was approximately $2: 1$. Nine of the 21 patients were reported to have been stillborn or died soon after birth. Longer survival (up to 22 years) has been reported in patients who did not have major organ malformations. ${ }^{16}$ Some patients had other phenotypic abnormalities in addition to the characteristic phenotype of duplication of the long arm of chromosome 6 . These additional characteristics are attributed to the varying length of the duplicated segment of chromosome 6 as well as to the differences in the deleted segments of the second chromosome involved in the translocation. ${ }^{9}$

The four cases with translocations involving the short arm of an acrocentric chromosome are crucial in delineating the true phenotype created by duplication of the distal long arm of chromosome 6 . These four patients do not have an associated deletion of any other chromosome. Although the duplicated segments of chromosome 6 vary in size, the region $6 \mathrm{q} 26 \rightarrow$ qter appears to be critical for the phenotypic characteristics of this syndrome. Additional material from the proximal long arm of chromosome 6 does not consistently alter the phenotype ${ }^{11}$ (table).

It appears that duplication of the distal long arm of chromosome $6(6 \mathrm{q} 26 \rightarrow \mathrm{qter})$ produces a distinct phenotype. Patients with a phenotype which includes microcephaly, acrocephaly, downward slanting palpebral fissures, telecanthus, micrognathia, carp shaped mouth, a characteristic short, anterior, webbed neck, club foot, joint contractures, and profound psychomotor retardation should be suspected of having a duplication of the distal long arm of chromosome 6 .

This investigation was supported in part by the Tennessee Fellowship contract Z-488850 from the Department of Mental Health and Mental Retardation and by the Genetics Program contract Z-35741 from the Department of Health and Environment, State of Tennessee.

1 Miller OJ, Miller DA, Tantravahi R, Dev VG. Nucleolus organizer activity and the origin of Robertsonian translocations. Cytogenet Cell Genet 1978;20:40-50.

2 de Grouchy J, Emerit I, Aicardi J. Trisomie partielle pour le bras long d'un C (?6) par translocation $\mathrm{t}(6 \mathrm{p}+; \mathrm{Cqs}+)$. Ann Genet (Paris) 1969;12:133-7.

3 Turleau C, de Grouchy J. Trisomy 6qter. Clin Genet 1981;19: 202-6.

4 Stamberg J, Shapiro J, Valle D, et al. Partial trisomy 6q, due to balanced maternal translocation $(6 ; 22)(q 21 ; p 13)$ or $(q 21 ; p t e r)$. Clin Genet 1981;19:122-5.

5 Taysi K, Chao WT, Monaghan N, Monaco MP. Trisomy $6 \mathrm{q} 22 \rightarrow 6 \mathrm{qter}$ due to maternal $6 ; 21$ translocation. Case report and review of the literature. Ann Genet (Paris) 1983;26:243-6.

6 Chen $\mathrm{H}$, Tyrkus $M$, Cohen $\mathrm{F}$, et al. Familial partial trisomy $6 \mathrm{q}$ syndromes resulting from inherited ins $(5 ; 6)(\mathrm{q} 33 ; \mathrm{q} 15 \mathrm{q} 27)$. Clin Genet 1976;9:631-7. 
7 Pierpont ME, MacCarthy KG, Knobloch WH. Partial trisomy 6q and bilateral retinal detachment. Ophthalmic Paediatr Genet 1986;7:175-80.

8 Schroer RJ, Culp DM, Stevenson RE, et al. Duplication deletion syndrome in a family with pericentric inversion of chromosome 6. Clin Genet 1980;18:83-7.

9 Tipton RE, Berns JS, Johnson WE, et al. Duplication 6q syndrome. Am f Med Genet 1979;3:325-30.

10 Schmid V, D'Apuzzo V, Rossi E. Trisomy 6q25 $\rightarrow 6 q$ ter in a severely retarded 7-year-old boy with turricephaly, bow-shaped mouth, hypogenitalism and club feet. Hum Genet 1979;46: 279-84.

11 Franchino CJ, Beneck D, Greco MA, Wolman SR. Partial trisomy 6q: case report with necropsy findings. $\mathcal{J}$ Med Genet $1987 ; 24: 300-3$.

12 Robertson KP, Thurmon TF, Tracy MC. Acrocephalosyndactyly and partial trisomy 6. Birth Defects 1975;11:267-71.

13 Fitch N. Partial trisomy 6. Clin Genet 1978;14:181-5.

14 Dallapiccola B, Bricarelli FD, Quartino AR, et al. Delineation of syndromes due to partial $6 \mathrm{q}$ imbalances: trisomy $6 \mathrm{q} 21 \rightarrow \mathrm{qter}$ and monosomy $6 \mathrm{q} 21 \rightarrow \mathrm{qter}$ in two unrelated patients. Acta Genet Med Gemellol (Roma) 1978;27:57-66.

15 Duca D, Bene $M$, Ioan D, Maximilian C. Familial partial trisomy: 6q25 $\rightarrow 6 \mathrm{qter} .7$ Genet Hum 1980;28:31-7.

16 Clark CE, Cowell HR, Telfer MA, Casey PA. Trisomy 6q25 $\rightarrow$ $6 \mathrm{qter}$ in two sisters resulting from maternal 6;11 translocation. Am 7 Med Genet 1980;5:171-8.

17 Neu KL, Gallien JU, Steinberg-Warren N, et al An infant with trisomy 6q21 $\rightarrow$ qter. Ann Genet (Paris) 1981;24:167-9.

18 Chase TR, Jalal SM, Martsolf JT, Wasdahl A. Duplication $6 \mathrm{q} 24 \rightarrow 6 \mathrm{qter}$ in an infant from a balanced paternal translocation Am 7 Med Genet 1983;14:347-51.

19 Enriquez-Guera MA, Rivera H, Moller M, et al. Trisomy 6qter resulting from a familial $(6 ; 10)(\mathrm{q} 23 ; \mathrm{q} 26)$ translocation. $\mathcal{f}$ Genet Hum 1986;34:327-30.

20 Miyabara S, Toyoshima H, Suzumori K. A fetal case of partial trisomy $6 \mathrm{q}(\mathrm{q} 2 \mathrm{l} \rightarrow \mathrm{qter})$ with renal dysplasia. $\mathcal{J p n} \mathcal{F}$ Hum Genet 1986;31:03,-9. 